\title{
Effects of additional weld and grinding on fatigue life extension of non-load-carrying cruciform joints*
}

\author{
by TSUTSUMI Seiichiro**, TAKATA Koyo *** and FINCATO Riccardo**
}

\begin{abstract}
Welded joints are often characterized by fatigue failure due to a series of factors such as stress concentration caused by bead geometry, changes in material properties by weld heat, and the effect of residual stresses. Grinding, TIG treatment, peening, etc., are available to improve the fatigue strength of weld joints. Also, the application of additional welding has been reported as one of the methods for reducing the stress concentration at the weld toe, with the consequential extension of fatigue life. A previous work reported that an additional weld could improve fatigue life of non-load-carrying fillet joints. The benefits of additional weld are also confirmed for the pre-fatigue damaged joints. Besides, grinding treatment achieves further improvement of fatigue life. However, additional weld and grinding treatments introduce geometrical and material changes such as the modification of the bead shape, angular distortions and welding residual stresses. In this study, the fatigue performance, in terms of crack initiation and propagation life, was numerically evaluated and compared with experimental results. Fatigue crack initiation and propagation life are evaluated based on cyclic elastoplastic FE and X-FE analyses.
\end{abstract}

Key Words: additional weld, grinding, Cross joint, Numerical analysis, Elastoplasticity, Angular distortion

\section{Introduction}

Fatigue failure of weld structures is often initiated around the welded parts due to a series of factors, such as stress concentration caused by the geometry of the welding bead, changes in material properties by heat input, residual stresses and deformations. On the other hand, grinding, TIG treatment, peening, etc., are available to improve the fatigue strength of welded joints ${ }^{1-14}$. Some of those methods have been standardized in JSSC ${ }^{3)}$ as improving methods to enhance the fatigue performance of joints. The application of additional welding is also one of the techniques adopted for reducing the stress concentration at the weld toe, and it is relatively easy to actuate $8,10,12-14)$

A previous work ${ }^{8)}$ reported that an additional weld could improve the fatigue life of non-load-carrying fillet joints. Benefits of the additional weld were also confirmed for the pre-fatigue damaged joints imitating the reinforcement process before cracking. Besides, the work also revealed that an additional improvement of fatigue life was achieved by a grinding treatment at the toe of the additional welding. However, the additional weld and grinding treatment have mixed contributions for fatigue life extension, such as changing the bead geometry, introducing angular distortions, residual stresses, surface roughness, etc. A clarification on the effects of each factor on the fatigue performance cannot be achieved only by an experimental study.

* Received: 2019.11.21, Presented at Visual-JW or WSE 2019

** Member, Joining and Welding Research Institute Osaka University

*** Student Member, Graduate school of Engineering Osaka University
In this work, fatigue performances on crack initiation and propagation lives were numerically evaluated and compared with experimental results ${ }^{8)}$ to understand the influence of additional welding and grinding treatment on fatigue strength of non-loadcarrying cruciform joints. Fatigue crack initiation and propagation life are predicted based on cyclic elastoplastic FE and X-FE analyses $^{10,13-16)}$, respectively. The bead geometry and the angular distortion of the joints used in the numerical analyses were extracted from the specimens used in the fatigue tests.

\section{Experiments}

Fig. 1 shows the results of the fatigue tests conducted by the coauthors ${ }^{5)}$. The fatigue test was conducted by means of a hydraulic servo test machine with the stress ratio $\mathrm{R}=0$. The non-load-carrying fillet joints were welded by gas shielded arc welding, using KA32 as base metal and MX-Z200 (T49J0T1-0CA-U) as welding wire.

The crack initiation life $(\mathrm{Nc})$ is defined as the number of cycles

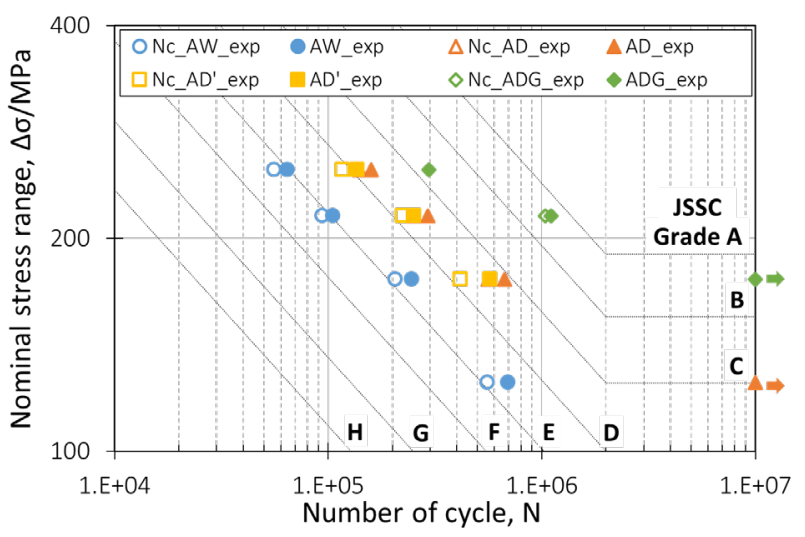

Fig. $1 \mathrm{~S}-\mathrm{N}$ curves $^{2)}$ 


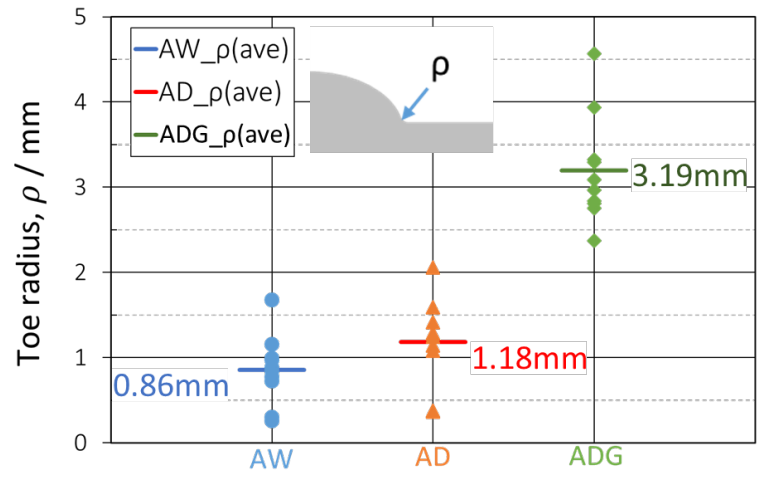

Fig. 2 Distribution of the toe radii

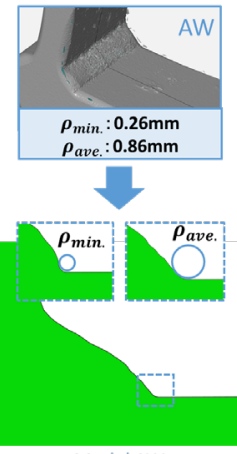

Model AW

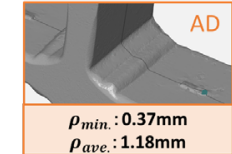

. $1.18 \mathrm{~mm}$

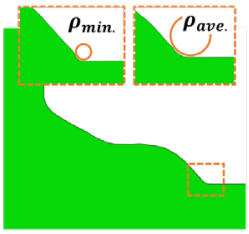

Model AD

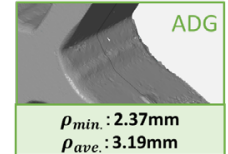

$\rho_{\text {ave. }}: 3.19 \mathrm{~mm}$

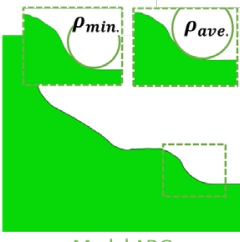

Model ADG
Fig. 4 FE model (2D)

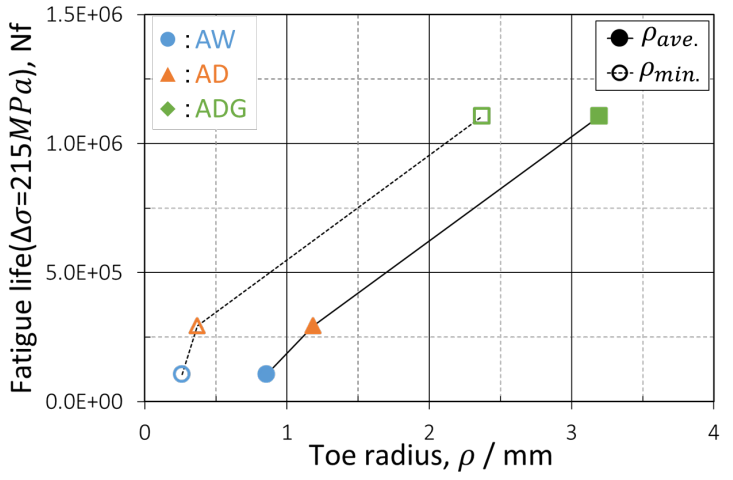

Fig. 3 Relationship between fatigue life and toe radius size

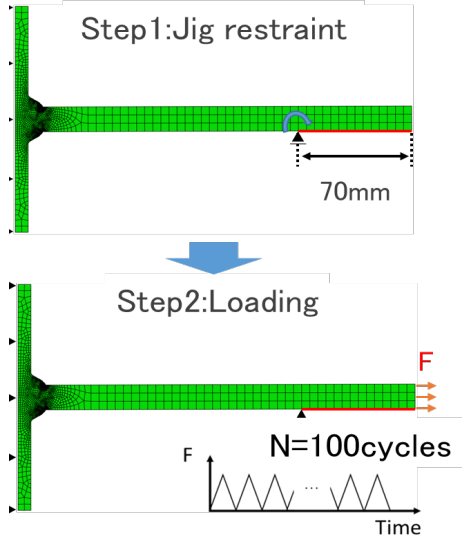

Fig. 5 Boundary conditions

Table 1 Outline of FE model

\begin{tabular}{|c|c|c|c|}
\hline Model name & AsWeld (Model AW) & D0 (Model AD) & 0.37 \\
\hline Minimum toe radius: $\rho_{\text {min. }}[\mathrm{mm}]$ & 0.26 & 1.18 & 2.37 \\
\hline Average toe radius: $\rho_{\text {ave. }}[\mathrm{mm}]$ & 0.86 & 0.32 & 3.19 \\
\hline Distortion angle: $2 \delta[$ deg.] & 0.32 & 0.56 \\
\hline
\end{tabular}

at which the response of the strain gauge, located at $5 \mathrm{~mm}$ from the weld toe, measures a $5 \%$ elongation compared to the beginning of the test. The fatigue experiments were carried out investigating 4 types of samples: AW (as weld), AD (additional welding), AD' (additional welding after pre-damage), ADG (additional welding and grinding after pre-damage). With the nomenclature "predamage" the authors mean that the sample has been subjected to a fatigue load of about $70 \%$ of the fatigue load applied in the fatigue life experiments of the AW case. As shown in Fig. 1, the fatigue life of the AW sample was improved approximately of one grade in the JSSC design curve by applying additional welding. By applying grinding to the additional weld joints, further improvement of another one grade was achieved. On the other hand, comparing the $\mathrm{AD}$ and the $\mathrm{AD}$ ' cases, it is possible to notice that the effect of pre-damage on fatigue life was negligibly small. Therefore, only the contribution of additional welding and grinding are considered in the analyses.
Fig. 2 shows the results of the toe radii measured in 10 points for each specimen. The smaller toe radii are obtained in the AW sample, followed by the AD and the ADG cases. This geometrical characteristic is correlated with the fatigue test results. Fig. 3 shows examples of the relationship between fatigue life for $\Delta \sigma=215 \mathrm{MPa}$ and the toe radii size (minimum and average radii), and it is possible to see the strong correlation between these two aspects. It is assumed that the change of the toe radii by the additional weld and the grinding has a great influence on the fatigue life extension.

\section{Numerical analysis}

\subsection{Analysis procedure}

The fatigue performance of the joints was evaluated numerically based on the prediction of fatigue crack initiation and propagation lives, where the bead geometry, angular distortion and changes in material properties by weld heat were considered ${ }^{9-14)}$. The FE 


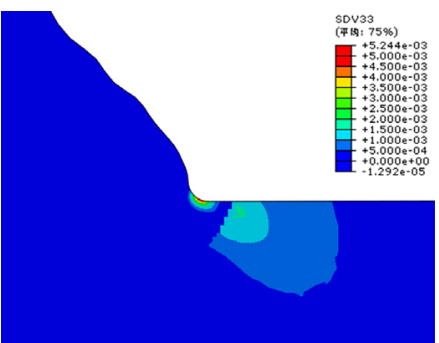

Model AW $(\Delta \sigma=215 \mathrm{MPa})$

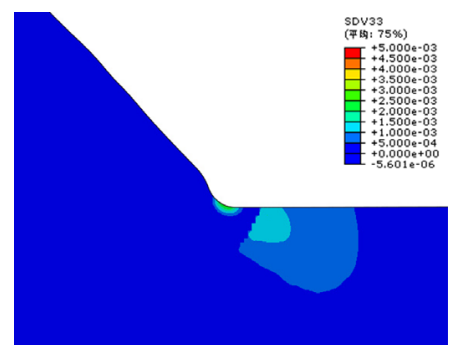

Model $\mathrm{AD}(\Delta \sigma=215 \mathrm{MPa})$

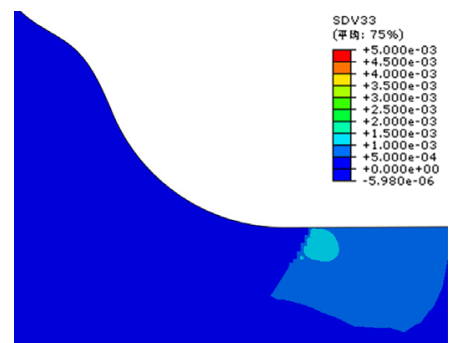

Model ADG $(\Delta \sigma=215 \mathrm{MPa})$

Fig. 6 Contour maps of the cumulative equivalent plastic strain (Minimum toe radius model)
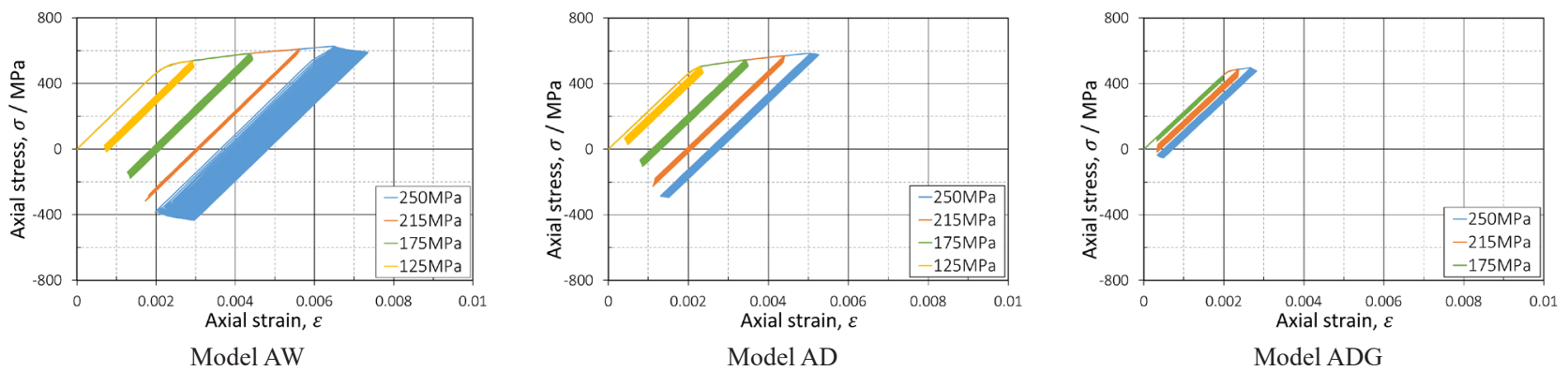

Fig. 7 Local stress-strain responses (Minimum toe radius model)

models were created based on the cross-sectional profile obtained by $3 \mathrm{D}$ shape measurements. Table 1 indicates the outline of the FE models. Two FE models, per each type of sample (AW, AD, ADG), were created by using the minimum and the average toe radii, respectively. Each sample is characterized by a different distortion angle as reported in Table 1. Fig. 4 and Fig. 5 show all the 2D FE models and the boundary conditions used in the numerical simulations. Since each FE model considers angular distortions, an initial rotational displacement is applied to the specimen in order to simulate the straightening induced by the jig restraints in the experimental tests ${ }^{8}$.

Then, cyclic elastoplastic FE analyses were carried out to evaluate the crack initiation life $\left(\mathrm{N}_{\mathrm{c}}\right)$. The consitutive model used in $\mathrm{FE}$ analyses is classified as an unconventional elastoplasticity model, named Fatigue $\mathrm{SS}^{16)}$, and it has been implemented via user subroutine for the commercial code ABAQUS. The loading conditions are the same as in the fatigue tests (stress ratio $\mathrm{R}=0$ ), and the number of loading cycles $\mathrm{N}$ was set to 100 . Similarly to a previous work ${ }^{15)}$, the material parameters assigned in the proximity of the weld toe considered the effect of the welding process on the metallic structure in terms of residual stresses, yield strength and tensile strength. The fatigue crack initiation life was evaluated based on the strain range magnitude $\Delta \varepsilon$. In this study, the following equations are used for calculating the crack initiation life $\left(\mathrm{N}_{\mathrm{c}}\right)$. Since fatigue life varies with the stress ratio, the original experimental equation ${ }^{2,10,14,15)}$ is improved by considering the function $\mathrm{A}\left(\sigma_{\mathrm{m}}\right)$ as in the following equation.

$$
\begin{aligned}
& \frac{\Delta \varepsilon_{t}}{2} \times A\left(\sigma_{m}\right)=0.415 N_{c}^{-0.606}+0.00412 N_{c}^{-0.115} \\
& A\left(\sigma_{m}\right)=\frac{225}{225-0.091 \sigma_{m}-0.0000895 \sigma_{m}^{2}}
\end{aligned}
$$

where $\mathrm{A}\left(\sigma_{\mathrm{m}}\right)$ is a function proposed in this study to consider the effect of the stress ratio ${ }^{13,16,18)}$.

Subsequently, the crack propagation life $\left(\mathrm{N}_{\mathrm{p}}\right)$ is calculated based on linear elastic fracture mechanics. The X-FE scheme was used to calculate the stress intensity factor (SIF) and crack growth path. The initial crack is inserted with a size of $0.05 \mathrm{~mm}$ at the predicted fatigue crack initiation point (located in correspondence of the element that showed the maximum cumulative equivalent plastic strain in the cyclic elastoplastic analyses). The crack propagation life $\left(\mathrm{N}_{\mathrm{p}}\right)$ is estimated using the SIF and the Paris' law for each crack length obtained in the analysis. The average design curve in the JSSC fatigue design guidelines ${ }^{1)}$ is used to calculate the parameter of the Paris law.

Finally, the total fatigue life $\left(\mathrm{N}_{\mathrm{f}}\right)$ is calculated as the sum of the crack initiation life $\left(\mathrm{N}_{\mathrm{c}}\right)$ and crack propagation life $\left(\mathrm{N}_{\mathrm{p}}\right)$. The effects of angular distortion and bead geometry changes on the fatigue life were investigated by comparing the experimental total fatigue life $\left(\mathrm{N}_{\mathrm{f}}\right)$ with the numerical results obtained considering the average and minimum toe radii models.

\subsection{Analysis results}

Fig. 6 shows the contour maps of the cumulative equivalent plastic strain after 100 loading cycles. The cumulative equivalent 
plastic strain is concentrated at the toe, with higher values obtained in the AW case with the smallest toe radius, followed by the $\mathrm{AD}$ and ADG samples. Fig. 7 shows the local stress-strain responses of the element characterized by the maximum cumulative equivalent plastic strain obtained in the elastoplastic analyses. As shown in Fig. 7, the additional weld and grinding reduced the generation of plastic strain and the

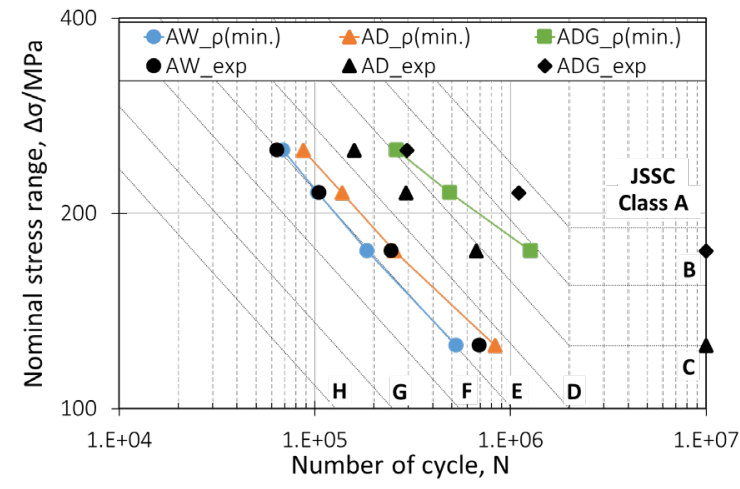

Fig. 8 S-N diagram (Minimum toe model)

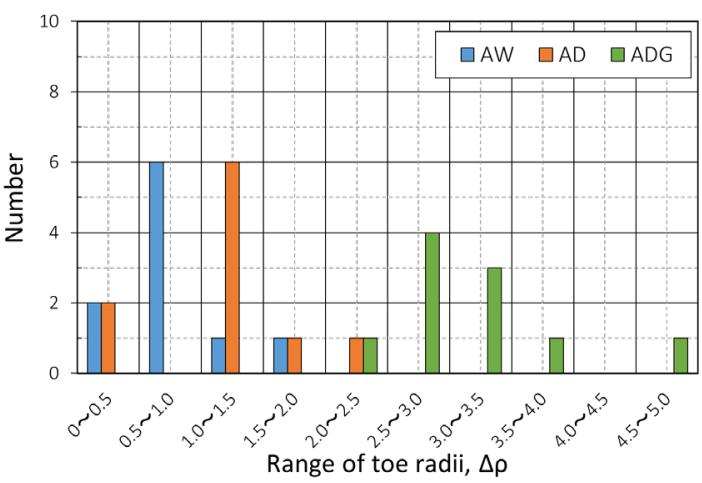

Fig. 10 Histogram of toe radii distribution

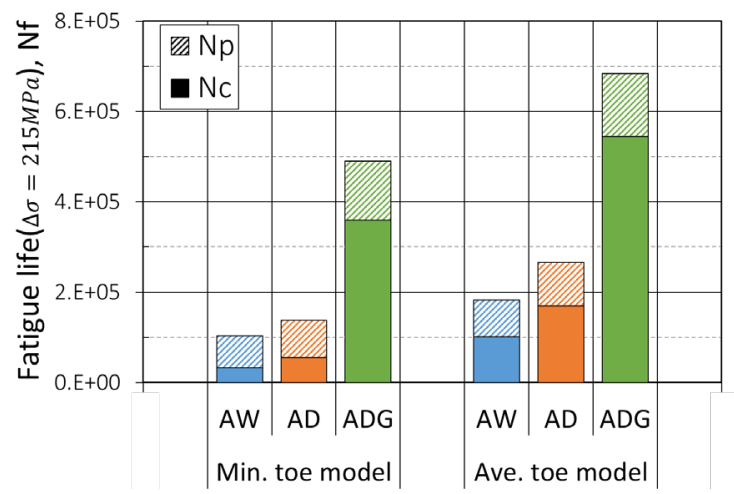

Fig. $12 \mathrm{~N}_{\mathrm{c}}$ and $\mathrm{N}_{\mathrm{p}}$ caluculation results $(\Delta \sigma=215 \mathrm{MPa})$

material ratcheting in the $\mathrm{AD}$ and $\mathrm{ADG}$ cases. Fig. 8 and Fig. 9 show the S-N diagrams containing the experimental data and the calculated total fatigue life $\left(\mathrm{N}_{\mathrm{f}}\right)$ of minimum toe and average toe models. In this study, the analysis is performed without considering the effects of residual stresses, but only the improved toe shape obtained by additional welding and grinding treatment, and the measured angular distortion. However, the numerical results seem to be in good agreement with the experimental data. It can be seen that the fatigue life is longer in the ADG case, followed by the AD and AW models. Therefore, it is considered that the fatigue life extension by the additional welding and the grinder treatment is greatly influenced by improving the toe shape. Also, considering the AW model with the minimum toe radius the

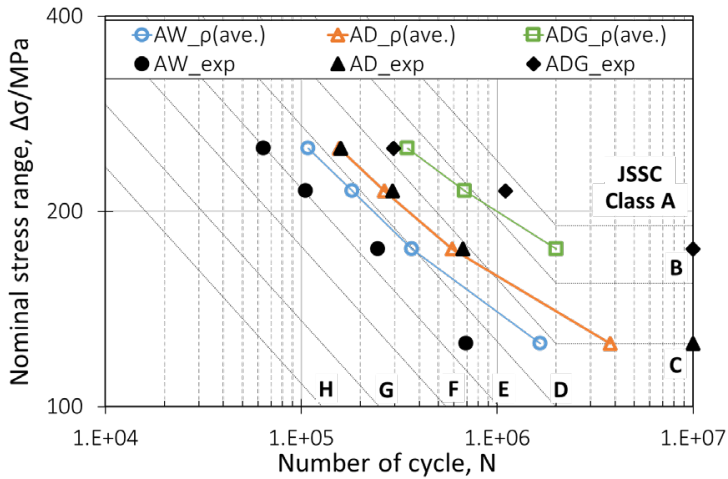

Fig. 9 S-N diagram (Average toe model)

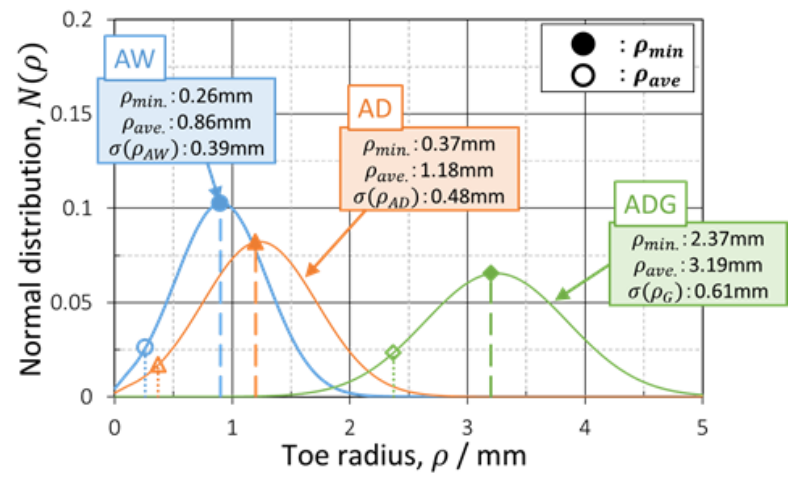

Fig. 11 Normal distribution of the toe radii

numerical simulation showed a better agreement with experimental results. On the other hand, the $\mathrm{AD}$ and $\mathrm{ADG}$ models with the average toe radius showed good agreement with the experimental results. Fig. 10 and Fig. 11 show the histogram of toe radii distribution and the distribution of the toe radii by a normal distribution. A previous work $^{1,}$ 6) reported that the stress concentration caused by local dent has a small effect on fatigue life. Furthermore, considering the model created by the average of the toe radii, it is confirmed that the stress concentration due to the local dent is larger than the one without the dent, even if the difference is not relevant. As shown in Fig.10, the number of samples having the toe radius close to the minimum toe radius in the $\mathrm{AD}$ and $\mathrm{ADG}$ cases is smaller than the average. Therefore, the influence of minimum toe radius is thought to be small in the AD and ADG models because the dispersion of the toe radii and the size differences between the minimum toe radius and the average toe radius are large. Whereas, in the AW case, the influence of the minimum toe radius is large because of the dispersion of the toe 
radii and the differences in size between the minimum and the average toe radii are small. Therefore, the minimum toe radius model is thought to have a high correlation with the experimental results in the AW case, whereas the average toe radius models have a high correlation with the experimental results in AD and ADG cases.

Fig. 12 shows the results of crack initiation life $\mathrm{N}_{\mathrm{c}}$ and propagation life $\mathrm{N}_{\mathrm{p}}$ for the minimum toe model and the average toe model obtained in the analyses $(\Delta \sigma=215 \mathrm{MPa})$. In the ADG model, $\mathrm{N}_{\mathrm{c}}$ is dominant in the total fatigue life $\left(\mathrm{N}_{\mathrm{f}}\right)$, whereas in the $\mathrm{AW}$ model, $\mathrm{N}_{\mathrm{p}}$ is dominant. This aspect could be attributed to the improvement of the toe shape in the ADG model that delays the crack formation.

\section{Conclusions}

The present work showed the numerical results obtained in 2D cyclic elastoplastic FE and X-FE analyses carried out to clarify the influence of the additional welding and grinding treatments on fatigue performance of non-load-carrying cruciform joints. The results can be summarized as follows.

1) There is a high correlation between toe radii and the fatigue life. Fatigue life is extended by improving the toe shape with additional welding and grinding treatment.

2) The crack initiation life $(\mathrm{Nc})$ is dominant in the ADG model with a long fatigue life, whereas the crack propagation life $(\mathrm{Np})$ is dominant in the AW model with a short fatigue life.

3) The minimum toe radius model in $2 \mathrm{D}$ has a high correlation with the experimental results in the AW case, whereas the average toe radius models have a high correlation with the experimental results in $\mathrm{AD}$ and $\mathrm{ADG}$ cases.

\section{Reference}

1) M. Onozuka, et.al.: Influence of Bead Toe Shapes on Fatigue Strength of Fillet Welds (2nd Report) -Fabrication Acceptance Level of Undercut Depths-, Journal of the Society of Naval Architects of Japan, 1992, 171, pp. 385-394, 1992

2) JSMS: Hirou Sekkei Binran, Yokendo Co.Ltd, (1995), 135.

3) JSSC: Fatigue design recommendations for steel structures, Gihodo Co.Ltd, 2012
4) C. Miki, et.al.: Fatigue Strength Improvement Methods by Treating the Weld Toe, Quarterly Journal of the Japan Welding Society, 17(1), pp.111-119, 1999

5) T. Mori, et al.: A Study on Method for Preventing Root Failure of Out-of-plane Gusset Welded Joints with Toe Grinding, JSSC: steel construction engineering, 16(63), p.27-35, 2009

6) T. Mori, et al.: Fatigue Strength of Cruciform Fillet Welded Joint with Undercut, JSSC: steel construction engineering, 19(76), p.4757,2012

7) D. Uchida, et al.: Influence of Grinding Depth on Fatigue Strength of Out-of-Plane Gusset Welded Joints with Finished Weld Toes, Steel Construction Engineering, 23(89), pp. 51-58, 2016

8) T. Shiratsuchi, et al.: Effects of Additional Welding at Weld Toe for Fatigue Strength of Welded Cruciform Joint, Proceedings of the Japan Society of Naval Architects and Ocean Engineers, 25, pp.347-352, 2017

9) T. Shiozaki, et.al.: Effect of weld toe geometry on fatigue life of lap fillet welded ultra-high strength steel joints, Int. J. Fatigue, 116, pp. 409-420, 2018

10) S. Tsutsumi, et.al: Assessment of fatigue crack initiation life of joints by using weld poor and cyclic plasticity analysis, Journal of Japan Society of Civil Engineers, Ser. A2, 74(2), pp. I_337-I_347, 2018

11) B. J. Mecséri, B. Kövesdi: Assessment of grinding weld treatment methods using effective notch stresses, Welding in the World, 64, pp.1033-1046, 2020

12) Y. Kotani, et.al.: Experimental Study for the Effect of Additional Weld on Fatigue Strength in Out-of-Plane Gusset Welded Joints, Quarterly Journal of the Japan Welding Society, accepted

13) S. Tsutsumi, et.al.: Numerical Study for the Effect of Shape of Additional Weld on Fatigue Strength in Out-of-Plane Gusset Welded Joint, Quarterly Journal of the Japan Welding Society, accepted

14) S. Tsutsumi, et.al.: Numerical study on the effect of weld bead shape on the fatigue crack initiation and propagation lives, Journal of Structural Engineering A (JSCE), 63A, pp. 609-618, 2017

15) T. Hiraide et al.: Effect of heat affected zone microstructure behavior under cyclic loading on fatigue life of weld joint, Quarterly journal of the japan welding society, 36(2), pp.145-151, 2018

16) S. Tsutsumi, et.al: Effect of local materials and geometries of weld joint root on fatigue crack initiation and propagation life, Journal of Japan Society of Civil Engineers, Ser. A2, 75(2), pp. I_467I_476, 2019

17) S. Tsutsumi, R. Fincato: Cyclic plasticity model for fatigue with softening behavior below macroscopic yielding, Materials \& Design, 165, 107573, 2019

18) H. Nishitani, et al.: Effect of mean stress on crack initiation and initial crack propagation in axial fatigue of an annealed $0.45 \% \mathrm{c}$ steel, Transactions of the Japan Society of Mechanical Engineers Series A, 50(460), pp.1926-1935, 1984 